\title{
A INSERÇÃO DE WALESKA PAIXÃO NA ENFERMAGEM
}

\author{
The introduction of waleska paixão in the nursing field \\ La inserción de waleska paixão en el campo de la enfermería
}

\section{RESUMO}

Este estudo apresenta dados históricos biográficos de Waleska Paixão (1903-1993), enfatizando diferentes momentos de sua vida pessoal e profissional. Descreve a sua inserção no campo da Enfermagem, analisando a sua trajetória de aluna, professora e diretora da Escola de Enfermagem Carlos Chagas e destacando as suas contribuições mais significativas na Associação Brasileira de Enfermagem. As fontes primárias fazem parte do acervo documental do Centro de Memória da Escola de Escola de Enfermagem da Universidade Federal de Minas Gerais e de depoimento oral de Waleska Paixão arquivado na instituição. Os resultados demonstram que a vontade e o desejo de adquirir, produzir, compartilhar e divulgar conhecimentos fazem parte da têmpora de Waleska Paixão, que se fez e foi se constituindo como figura ímpar no ensino e na prática da enfermagem, mostrando o seu envolvimento com o campo da educação e da saúde e algumas de suas contribuições para o desenvolvimento da enfermagem brasileira.

Palavras-chave: História da Enfermagem. Biografia. Escolas de Enfermagem

\section{Abstract}

This study presents a biographic historical data of Waleska Paixão (1903-1993), emphasizing different moments of her personal and professional life. It describes her introduction in the Nursing field, analyzing her path as student, teacher and director of Carlos Chagas Nursing School, highlighting her most significant contributions to the Brazilian Nursing Association (Associação Brasileira de Enfermagem). The primary sources belong to the documentary collection of the School Memorial Center of the Nursing School, Federal University of Minas Gerais and to Waleska Paixão's oral testimony filed in the institution. The results show that the will and wish to acquire, produce, share and spread knowledge are part of the way of Waleska Paixão, who grew up professionally by herself and started to be considered as unique in the teaching and practice of nursing, showing her involvement with the field of education and health and some of her contributions to the development of Brazilian nursing.

Keywords: History of Nursing. Biography. Nursing Schools

\section{Resumen}

Este estudio presenta datos históricos de Waleska Paixão (19031993), haciendo hincapié en los diferentes momentos de su vida personal y profesional. Describe su inserción en el campo de la enfermería, analizando su trayectoria como alumna, profesora y directora de la Escuela de Enfermería Carlos Chagas y destacando sus contribuciones más importantes junto a la Asociación Brasileña de Enfermería (Associação Brasileira de Enfermagem). Las fuentes primarias hacen parte de la colección documental del Centro de Memoria de la Escuela de Enfermería, Universidad Federal de Minas Gerais y del testimonio oral de Waleska Paixão, archivado en la institución. Los resultados muestran que la voluntad y el deseo de adquirir, producir, compartir y difundir el conocimiento forman parte de la forma de vivir de Waleska Paixão, que se hizo y se fue construyendo como personalidad única en la enseñanzay la práctica de la enfermería, mostrando su participación en el ámbito de la educación y la salud y algunas de sus contribuciones al desarrollo de la enfermería brasileña.

Palabras clave: Historia de la Enfermería. Biografía. Escuelas de Enfermería

\footnotetext{
'Doutora em Educação pela Faculdade de Educação da Universidade Federal de Minas Gerais. Professora Adjunta do Departamento de Enfermagem Básica da Escola de Enfermagem da UFMG. Subcoordenadora do Centro de Memória da Escola de Enfermagem da UFMG. Membro do Núcleo de Pesquisas e Estudos sobre o Quotidiano em Saúde. Brasil. E-mail: gfortina@ufmg.br, ${ }^{2}$ Enfermeira. Mestre em Enfermagem pela UNI-RI0. Professora Assistente (aposentada) do Departamento de Enfermagem Básica da Escola de Enfermagem da UFMG. Membro da Coordenação do Centro de Memória da Escola de Enfermagem da UFMG e do Núcleo de Pesquisas e Estudos sobre o Quotidiano em Saúde Brasil. E-mail: valdacaldeira@yahoo.com.br, ${ }^{3}$ Aluna de Graduação em Enfermagem da EEUFMG. Membro do Núcleo de Pesquisas e Estudos sobre o Quotidiano em Saúde. Brasil. E-mail: Sabrina_antonieta@hotmail.com
} 


\section{INTRODUCÃO}

Certamente, os enfermeiros que estudaram em escolas brasileiras a partir da década de 1950 devem ter ouvido alguma menção a respeito de Waleska Paixão. A sua presença nas Páginas de História da Enfermagem ${ }^{1}$, livro de sua autoria, publicado em 1951, faz dela a primeira historiadora enfermeira do País. No prefácio da primeira edição do livro, sabedora da escassez bibliográfica na área da enfermagem, situação presente até há poucos anos atrás, Waleska Paixão demonstra a sua preocupação com o ensino de história da enfermagem ao dizer: "representam estas páginas apenas uma pequena contribuição para a formação de nossas profissionais" e "apesar de modesta, resolvi publicá-las, para diminuir um pouco as dificuldades de professores e alunas" "1: . Acrescenta que o livro foi fruto dos doze anos em que lecionou História da Enfermagem, nove dos quais na Escola de Enfermagem Carlos Chagas (EECC). 0 livro "tornou-se best sellere, depois de 53 anos e cinco edições, continua sendo apontado informalmente como referência para o estudo e a pesquisa em História da Enfermagem":2182.

A vontade e o desejo de adquirir, produzir, compartilhar e divulgar conhecimentos fazem parte da têmpera dessa personagem ímpar da enfermagem brasileira. É isto o que tem demonstrado as pequenas biografias ${ }^{2,3-4}$ escritas sobre ela por pesquisadores interessados em estudos e pesquisas em história da enfermagem. É impossível estudar a evolução da enfermagem brasileira sem fazer alguma menção a ela.

A escritura sobre a vida de Waleska Paixão é uma forma de escrever sobre a história da enfermagem brasileira, pois ela foi ator social e uma das protagonistas dessa história. As suas contribuições para os avanços da enfermagem e para a evolução do ensino da profissão no Brasil são reconhecidas com a sua inserção no "banco de dados denominado Quem é Quem na História de Enfermagem Brasileira, do Núcleo de Pesquisa de História de Enfermagem Brasileira-Nuphebras"5.

As razões que nos levaram a propor este estudo estão relacionadas ao nosso interesse e motivação por pesquisas sobre a profissão enfermagem, particularmente a sua história, a nossa trajetória na docência de enfermagem, bem como a maior visibilidade que os estudos biográficos vêm adquirindo no campo da história da enfermagem.

Nesse sentido, esperamos contribuir com os estudos históricos da profissão, trazendo novos elementos da trajetória pessoal e profissional dessa enfermeira que dedicou a sua vida ao serviço da educação em enfermagem.

\section{PERCURSO TEÓRICO-METODOLÓGICO}

Este trabalho, de natureza histórico-social, tem como objetivo descrever as circunstâncias relativas à inserção de Waleska Paixão (1903-1993) na enfermagem. Especificamente, o presente estudo buscou apresentar dados biográficos de Waleska Paixão; analisar a sua trajetória de aluna, professora e diretora na Escola de Enfermagem Carlos Chagas (EECC); e destacar as suas contribuições mais significativas junto à Associação Brasileira de Enfermagem (ABEn). As fontes primárias fazem parte do acervo documental do Centro de Memória da Escola de Enfermagem da UFMG e as secundárias foram constituídas por livros, teses e artigos de periódicos que tratam da história da enfermagem e da história da educação. $A$ consulta ao acervo foi feita nos meses de maio e junho de 2008.

Destaca-se, ainda, que ao privilegiar a descrição da trajetória de Waleska Paixão na EECC e junto à ABEn, o recorte temporal da pesquisa abrange as décadas de 1930 a 1960.

No decorrer do processo de investigação, ao proceder à análise documental, por meio de sucessivas leituras e apreciação crítica na construção das fontes, buscamos atender aos objetivos propostos pelo estudo

\section{RESULTADOS}

\section{Waleska Paixão por outrem e por ela mesma}

A biografia, a escrita sobre o outro, assim como autobiografia, a escrita sobre si, são mecanismos sociais "que favorecem ou autorizam a experiência comum de vida como uma unidade e como totalidade" $6: 186$. São essas escritas relatos de vida - que permitem uma interpretação do indivíduo, devolvendo ao social um sentido e um significado para a ação de seus sujeitos.

Não há como perguntar à Waleska Paixão quem ela ée o que ela foi. Mas é possível a construção de algumas respostas, quase sempre seguindo o mesmo itinerário: origem social e geográfica, formação e atuação profissional.

Com poucas variações, as fontes consultadas informam que Waleska Paixão nasceu em 3 de novembro de 1903, em Petrópolis, cidade do Rio de Janeiro, filha de Dr. Henrique Paixão e de Ludovina Vale da Paixão.

Pertencia a uma família em que todos se encaminhavam para profissões liberais e para o magistério. Seu avô fundou o Colégio Paixão, um dos mais tradicionais da cidade, "onde o imperador gostava de descansar o espírito, em visitas frequentes e demoradas, terçando sabedoria com os alunos" 5:60. A literatura e a música faziam parte da formação 
de seus familiares. "Suas tias frequentavam o Palácio Imperial, onde abrilhantavam os serões e o coro da Capela, com seus dotes musicais" ${ }^{\prime 3: 60}$. Nesse ambiente de grande efervescência cultural e intelectual, Waleska ingressou muito cedo na escola, considerando que poucas mulheres tinham acesso à escola, nessa época. Ao terminar o curso secundário passou a atuar como professora do curso primário do Externato Paixão, dirigindo este Colégio em diversos períodos. Nessa época ministrou, também, aulas de Francês e de Matemática no Curso Ginasial do Colégio Notre Dame de Sion.

Aos 15 anos de idade começou seu envolvimento com a Enfermagem. A doença de uma de suas irmãs levou-a a aprender a aplicar injeção. A partir daí, começou a ser chamada para atendimento domiciliar. Nessas visitas, buscava atender não só o que fora recomendado pelo médico. Atendia aos doentes, atentando para detalhes como a alimentação, 0 posicionamento, a necessidade que eles tinham de ser ouvidos ${ }^{4}$. É Waleska quem relata as suas primeiras aproximaç̃̃es com o "lidar com os doentes", pensando no bem-estar dos mesmos.

Então, aos quinze anos, realmente eu comecei a lidar com os doentes, aqui, acolá, e quando o doente era muito pobre, então, a gente sentia aquela preocupação de ter um doente que não tinha o alimento satisfatório, que não tinha em casa quem cuidasse, desse um pouco de conforto. Aquelas coisas básicas da enfermagem eu, intuitivamente, ia achando que eram necessárias. Ver um doente em cima de uma cama, que não tinha um lençol pra mudar. Eoutras coisas, achei o travesseiro duro, achei uma coisa pra botar no cotovelo. Então comecei a pensar no bem-estar do doente. (...) Enessas visitas, muitas vezes eu sentia o doente rico, que tinha falta de alguma coisa porque não tinha quem ficasse e quem o ouvisse. Então comecei a aprender a ouvir tanto quanto me permitia o tempo disponivel:1.

Contudo, apesar da sua identificação com a enfermagem e do seu desejo de cuidar de doentes, Waleska sabia que a sua família não concordaria com seu ingresso na profissão. Ela revelou que aos 19 anos viu um anúncio de curso de enfermagem da EEAN e teve vontade de matricular-se. Mas tinha certeza de que a sua mãe não iria deixar, pois, "naquele tempo, praticamente enfermagem não existia. Era exercida por pessoas de nível bastante baixo, às vezes boas, mas sem uma certa visão. (...) Por outro lado, nesse tempo, eu estava pensando muito na vida religiosa. Quando eu era menina, vi que as irmãs de caridade é que deviam cuidar dos pobres" $": 2$.

0 trabalho da enfermagem, em seus primórdios, compreendia, segundo ela, três elementos principais: o espírito de serviço (ou ideal), a habilidade (arte) e a ciência. 0 espírito de serviço teria sido o primeiro em ordem cronológica e de importância, pois, quando
não havia ciência" (sic), era ele que realizava, já embrionariamente, aquilo que ainda hoje constitui alguns dos objetivos da enfermagem: dar conforto físico e moral ao doente, afastar dele os perigos, ajudá-lo a alcançar a cura. A arte foi-se formando em seguida, de mistura com superstições e conhecimentos empíricos. Só mais tarde veio a verdadeira ciência ${ }^{8}: 19$.

Nessa cosmovisão, destaca-se o seu aguçado e marcadamente proclamado lema em prol da humanidade: 0 "espírito de serviço". Waleska Paixão relata que aos 24 anos de idade um padre missionário francês, em visita ao Brasil, não sossegou enquanto não a convenceu que ela deveria ir à França para aperfeiçoa-ser em catequese. Então, "passei um ano e meio na França e foi muito proveitoso mesmo e gostei imensamente. Agora, lá não cogitei enfermagem. Eu estava concentrada naquele estudo de catequese" $1: 2$.

Curiosamente, a sua reaproximação com a enfermagem deu-se com uma situação de doença e em decorrência de sua grande amizade com Laís Netto dos Reys que "tinha ido pra Belo Horizonte e estava começando uma Escola de Enfermagem lá." (...) "Então ela me convidou para passar um ano lá porque eu estava nessa ocasião com hipertireoidismo. Eu passei tão mal, fiquei tão ruinzinha mesmo! Aí eu entendi mais enfermagem. Foi a necessidade que o doente tem de compreensão"::3.

É importante destacar que Laís Netto dos Reys foi organizadora da EECC e sua primeira Diretora. Ademais, ela e Waleska Paixão foram mulheres brasileiras que exerceram marcante militância na educação da enfermagem brasileira. A atuação dessas protagonistas no campo da enfermagem e da saúde pode ser analisada na perspectiva apresentada por Pierre Bourdieu, em relação ao uso que ele faz de campo de poder. Elas teriam sido mulheres que se apropriaram de capital do campo econômico, social e cultural em que a noção de campo de poder é usada para designar "as relações de forças entre as posições sociais que garantem aos seus ocupantes um 
quantum suficiente de força social - ou de capital - de modo a que estes tenham possibilidade de entrar nas lutas pelo monopólio do poder" ${ }^{\prime 2: 28-9}$.

Apropriando-se desse capital sociocultural, Waleska Paixão, morando em Belo Horizonte, foi convidada por um padre para dar continuidade a seus estudos missionários iniciados na França, participando dos trabalhos de catequese. Aceitou ao convite e, após um ano de licença-saúde, "melhorando a catequese de Belo Horizonte" ": (sic), deveria voltar para o Externato Paixão, em Petrópolis/RJ, onde ainda mantinha vínculos profissionais. Entretanto, ela não retornou, conforme relato a seguir:

D. Laís vira-se pra mim e disse: "Olha, agora que você está mais forte, você podia dar umas aulas pras enfermeiras". Eu disse: "Mas eu vou dar aulas para enfermeira? Aula de quê pros alunos". Ela disse: "Vou te dizer, tem um livro de drogas e soluções. As enfermeiras que me ajudam tem horror à matemática. Então você pode ensinar aquilo porque não é propriamente enfermagem. É uma coisa química e a parte de cálculo..." "Está bem". "E também o professor de psicologia tem que sair diz que tem que sair por algum tempo e você podia substituí-lo":3.3.

Assim, em 1935, Waleska Paixão inicia sua trajetória como docente, e, posteriormente, como aluna na EECC. No período de 1935 a 1948 ela ministrou disciplinas, tais como: Ética e História da Enfermagem; Enfermagem Cirúrgica; Português; Matemática; Cálculos eSoluções; Psicologia; Nutrição; Higiene Geral e Histologia. Além da sua facilidade e disponibilidade para atuar em diferentes e diversas áreas de conhecimento, destaca-se o seu ótimo humor ao relatar o início da sua inserção formal na enfermagem:

Então comecei na Escola como professora, depois passei a aluna (RISOS). Assim foi indo...,(...) e morava no internato, com elas, com as alunas e chegou uma hora que eu pensei: "Bem, há muito tempo que eu lido com doentes. Agora eu encontro uma escola aqui à mão, já estou mais idosa [31 anos], não sou mais criança que mamãe não deixaria estudar. Então o horror todo era a gente se meter em obstetrícia. É a tal história de se dizer: Gente, se uma pessoa já tem idade de ter um filho, já tem idade pra ajudar outra que vai ter um filho" "7:3-4.
Com este depoimento Waleska declarou-se, nessa época, prontamente amadurecida para dedicar-se à enfermagem, apesar de já ter demonstrado, desde muito cedo, o seu interesse em trabalhar a serviço da humanidade, em profissões que the permitissem desenvolver o cuidar do outro. Ou seja, teve uma formação escolar bastante cedo e, profissionalmente, pôde exercer o cuidar, atuando no magistério. E, aos 31 anos de idade decidiu, por forte influência de Laís Netto dos Reys, cursar enfermagem.

Paraingressar no Curso de Enfermagem, o curso secundário que fizera não era reconhecido. Assim, ela prestou exames, entre 1935 e 1937, no Ginásio Dom Silvério, em Sete Lagoas, Minas Gerais, e obteve a documentação necessária para iniciar o curso na EECC.

A ficha de inscrição das candidatas consistia no principal instrumento do processo de seleção ao Curso de Enfermagem Geral, naEECC ${ }^{10}$. Nessaficha, além da identificação na qual constava o nome, a idade, o endereço e a pessoa da família ou outro responsável pela candidata, era possível avaliar: instrução, ocupações anteriores, características e referências pessoais, práticas anteriores na enfermagem e a descrição sobre as ideias, o objetivo e os motivos que levaram a candidata a optar pela profissão. № preenchimento da ficha, Waleska Paixão fez o seu depoimento sobre a sua opção pela enfermagem:

Não é sempre fácil dizer porque abraçamos uma profissão, mormente em casos como o meu, já no meio da vida, depois de trabalhar mais de 15 anos numa carreira abraçada por uma verdadeira e profunda vocação, por que mudar? Inconstância? Meio de ganhar mais facilmente a vida? Entusiasmo, ao descortinar as belezas de uma carreira como a Enfermagem, na qual os sentimentos tão femininos de compaixão pelos que sofrem encontram largo escoamento? Tudo isso é belo, certamente, mas não é essa a verdade; e os motivos de minha decisão por demais complexos não caberiam neste espaço. Seja-me pois, permitido dizer que julgo compreender o objetivo da Enfermagem, não a nivelando com uma profissão qualquer. Assim como a Educação é um terreno onde não dará bastante quem não se der inteiramente; não é apenas uma profissão - é uma vocação. Assim considerada, a assistência aos doentes ultrapassa o seu fim material, atinge também o moral. Uma vez diplomada, porei a Enfermagem a serviço da Educação ou meus conhecimentos pedagógicos a serviço da Enfermagem? É o que ainda está por 
A inserção de Waleska Paixão no campo da

\section{enfermamagem}

Santos GF, Caldeira VP, Moreira SA

decidir. Em qualquer caso, porém, será o serviço ao próximo pelo amor de Deus ${ }^{11}$.

A descrição de Waleska Paixão, particularmente, revela o dilema da candidata em optar pela enfermagem em detrimento do magistério uma vez que as duas profissões exigem para o seu exerćcio a mesma vocação. Além disso, o relato deixa em evidência a natureza feminina e o imbricamento dos campos de ação dessas profissões. Ao questionar se colocará a Enfermagem a serviço da Educação ou seus conhecimentos pedagógicos a serviço da Enfermagem, o que sobressai é o campo da educação, bem como o da saúde. Destacase que, nessa época, na sociedade brasileira, esses campos estavam sendo reordenados com a instituição e a imposição de novas medidas de educação e de saúde - a higienização dos costumes - à população, exigindo o trabalho de educadoras dessas profissionais, professoras e enfermeiras.

Se naquele momento, Waleska Paixão teve dúvidas sobre a sua dedicação à educação ou à enfermagem, a sua trajetória como professora de enfermagem mostra que ela trabalhou intensamente pela melhoria da qualidade do ensino de enfermagem e pela formação de enfermeiras moral, ética e socialmente comprometidas com o doente, com a saúde da população e com a profissão. Ademais, em poucos anos, ela percorreu os caminhos de aluna, professorae diretora:

Ao iniciar o curso, em 1936, viveu a contradição de ser ao mesmo tempo, professora e aluna. Em 21 de novembro de 1938, terminou o curso de Enfermagem e, quatro meses depois, assumiu a direção da EECC. No cargo continuou enfrentando a dificuldade de atender todas as exigências necessárias para a equiparação da Escola ao padrão oficial. Essa meta foi alcançada em 1942, durante a sua gestão $0^{451}$.

Durante a sua permanência na EECC, Waleska Paixão, exerceu, também, a função de Inspetora das alunas e, em uma das reuniões em que se discutia a organização e o funcionamento do Internato da Escola, ela sugeriu a criação de um Grêmio e de um órgão literário a ele associado. De acordo com a aluna que elaborou o "histórico do Internato", "foi escolhido o nome ‘9:55' para o Grêmio e '5 p'ras 10' para o órgão oficial do mesmo, porque é esta a hora do sinal de silêncio"12:57. 0 Jornal Cinco p'ras Dez exigia, para a sua elaboração, redação e divulgação, e a participação compulsória das alunas, das professoras e dos demais moradores do internato. As matérias e as notícias, apresentadas em prosa eversos, informavam o dia-a-dia da Escola ${ }^{10}$. A contradição vivenciada em ser aluna e professora é manifestada nos seus escritos, aflorando a sua veia literária, servindo-se de estímulo e exemplo para suas colegas e
Esc Anna Nery Rev Enferm 2010 abr-jun; 14 (2): 268-274

alunas. Asua participação de todos os moradores do internato da EECC com matérias para este jornal é muito expressiva, sendo ele considerado, na época, o porta voz da Escola.

Ao colocar o Jornal como o porta-voz da Escola, Waleska Paixão diz que o Cinco p'ras Dez:

deixará gravadas as grandes datas da Escola e dirá às colegas que nos sucederem que suas irmãs mais velhas trabalharam para o futuro, desejaram firmar as tradições da casa e legar-thes com o exemplo da boa vontade e do esforço para melhorar, um espirito de cooperação... impregnado de caridade, que nos torne a todas menos indignas do ideal de cristãs, Enfermeiras e Brasileiras ${ }^{13: 5 p}$.

Atendendo exigência para o exerćício do cargo de Diretora de Escola de Enfermagem, WaleskaPaixão teve que complementar sua formação. Para tanto, fez, em 1943 e 1944, o curso de Administração e Ensino, nos Estados Unidos. Com bolsa de estudos do Instituto de Assuntos Interamericanos, ficou dez meses na Universidade de Cornell, em Nova lorque, Estados Unidos, onde fez estágios, visitou escolas e serviços de saúde. ${ }^{4}$ Ao regressar dos Estados Unidos, preocupada em formar novos líderes da enfermagem, ela indicou o nome de Celina Viegas, egressa e instrutora de enfermagem daEECC, parafazer a complementação de estudos naquele Instituto. A sua indicação teve imediata repercussão, e Celina Viegas organizou e dirigiu a Escola de Enfermagem Hermantina Beraldo, em Juiz de Fora, Minas Gerais, criada pelo Departamento Estadual de Saúde, em 1946. ${ }^{14}$

Tratando-se do período de sua gestão na EECC, Waleska Paixão destaca dificuldades vivenciadas:

Eu acho que não tem nenhuma Escola que não tenha algum pontinho fraco, não? Mas a nossa tinha que ter vários pontos porque era uma coisa que estava começando. Eu seique, quando ela [Laís Netto dos Reys] apresentou a coisa aqui no Rio, não deram a equiparação. Nós continuamos "lança livre", e láfui eu lecionando e estudando. Eu era professora de minhas colegas em algumas matérias. Bom, quando terminei o curso, D. Laís tinha sido nomeada para diretora da Anna Nery, estava de saída e a vicediretora, que ela tinha levado, era antiga da Anna Nery também, mas não era pessoa de visão largamuito boa - entregou-se a ela parte da saúde publica, e ela caprichava naquilo, mas não tinha aquela visão larga de chegar e dirigir uma escola. Então, a própria D. Laís foi lá na Secretaria de Educação e disse que menomeassem diretora da Escola, de modo que eu 
mudei o vestido branco, que lá se usava vestido azul. Quando mudei o vestido branco, fui tomar posse da direção da Escola de Belo Horizonte ${ }^{7: 45}$.

Durante o período em que permaneceu em Belo Horizonte (1935-1948), além das atividades na EECC, Waleska Paixão colaborou em trabalhos de catequese, fez cursos de Teologia e Filosofia no Instituto Superior de Cultura Católica; lecionou Francês e Matemática no Colégio Santa Maria e na Escola de Comércio de Belo Horizonte. ${ }^{4}$

Em 1948, Waleska Paixão demitiu-se da EECC. A sua decisão em demitir-se do cargo de diretora foi devida a sua discordância com a ideia do recém-empossado Diretor de Saúde Pública da Secretaria de Educação e Saúde Pública do Estado de Minas Gerais que pretendia reestruturar a Escola para que ela atuasse apenas na formação de enfermeiras de saúde publica. De acordo com ela "o diretor da Saúde Pública inventou que ele ia fazer uma reforma na Escola só pra enfermeiras de Saúde Pública. E eu cansava de explicar a ele, como ela pode ser enfermeira da Saúde Pública se ela não sabe o resto dos problemas da saúde?":114. Assim, sem conseguir demovê-lo da ideia, Waleska Paixão deixou a direção da EECC. Após contato com Laís Netto dos Reys, mudou-se para o Rio de Janeiro em maio do mesmo ano. Nesse sentido, Waleska Paixão, estando apta a assumir direção de Escolas de Enfermagem, tornou-se, novamente, sucessora de Laís Netto dos Reys, em 1959, iniciando sua trajetória na EEAN.

Dos atributos que emergem das biografias para fazer de Waleska Paixão uma personagem de destaque no campo da enfermagem brasileira, ressalta-se a sua versatilidade. "Ao enumerar as atividades de Waleska Paixão, não se encontra sequer um ângulo em que ela não tenha atuado com brilho, proficiência e humildade. É como se vocêestivesse brincando com um caleidoscópio e, a cada movimento de sua mão, deparasse com figuras surpreendentes ${ }^{13: 60}$.

\section{Contribuindo para os avanços da enfermagem como profissão na ABEn}

Em seu permanente trabalho nos diversos cargos que exerceu na ABEn, denominada Associação Brasileira de Enfermeiras Diplomadas (ABED) até 1954, Waleska Paixão atuou de forma decisiva em matérias que exigiam posicionamentos competentes para com os Órgãos de Legislação sobre a educação brasileira e o ensino de enfermagem, em particular.

Em 1943, percebendo que o despreparo das enfermeiras no tocante a aspecto de administração dificultava o trabalho delas enquanto chefes de serviço, Waleska Paixão criou e coordenou um grupo de estudos formado por enfermeiras, para buscar soluções para o referido problema.

Em 1946, a ABEn instituiu a Divisão de Educação e a Divisão de Saúde Pública. Como membro da Divisão de Educação, Waleska Paixão, juntamente com Edith Fraenkel, Laís Netto dos Reys, Celina Viegas e outras docentes de enfermagem, participou de comissão que deu continuidade na busca de alternativas para " assegurar às enfermeiras diplomadas 0 tipo de preparo necessário ao bom desempenho de suas funções” 15:127. Esta Comissão foi constituída para estudar a organização de cursos para formação de enfermeiras chefes e instrutoras, uma necessidade reconhecidamente unânime pelas sócias da ABEn.

Em 1947, Waleska Paixão fundou a ABEn, Seção Minas Gerais, a quarta do país, e foi presidente até 1949. Simultaneamente foi Membro do Conselho Fiscal da ABEn Nacional.

Tratando-se do estatuto daABEn, por esta Associação ser considerada entidade de utilidade pública, o Ministério da Justiça exigiu que deveria constar que os cargos de Diretoria e de Conselho Fiscal não eram remunerados. Enquanto Presidente da ABEn (1950-1952), Waleska Paixão informou em assembleia geral extraordinária, em 17 de abril de 1952, que o estatuto não havia sido registrado desde 1944. Propôs reformas para atender tais exigências e providenciou o registro do estatuto com as emendas aprovadas.

Destaca-se ainda que, de 1947 a 1953, na condição de Presidente daABEn e de Diretora de escola de enfermagem, Waleska Paixão foi redatora da Revista Brasileira de Enfermagem. Nessa função ela lutou pela qualidade da revista, seja criticando as falhas observadas, seja fazendo doações financeiras para sua sobrevivência. Ademais, resgatando experiência iniciada enquanto diretora de EECC, ela presidiu, em 1954, a Comissão Permanente de Diretoras de Escola, órgão técnico de consulta da Divisão de Educação. Em seu permanente trabalho nessa Divisão, Waleska Paixão muito contribuiu para traçar as diretrizes para o ensino de enfermagem, sendo designada pela Portaria do Ministério da Educação nº. 456, de 24 de dezembro de 1956, para estudar o problema da reforma do ensino e apresentar sugestões para elaboração de anteprojeto de lei. Como resultado desse trabalho, entregou, em menos de 30 dias, o estudo Dados para a Lei Orgânica do Ensino da Enfermagem ${ }^{15}$.

Em sua luta constante pela valorização e divulgação da profissão, em 1961, ela participou de campanha intensiva para recrutamento de candidatas, percorrendo escolas, associações recreativas, organizações religiosas e estabelecimentos industriais e comerciais. Fez ainda gestões no âmbito dos Ministérios da Saúde e da Educação para que 
fossem concedidas bolsas de estudos ou licença com vencimento para funcionárias da área burocrática que ingressassem em cursos de Enfermagem ${ }^{6}$.

Em 1965, quando as questões relacionadas ao ensino superior, dentre elas o da enfermagem, já era da competência exclusiva do Conselho Federal de Educação, criado após a primeira Lei de Diretrizes e Bases da Educação Brasileira promulgada em 1961, Waleska Paixão participou de comissão para revisão do currículo mínimo de enfermagem vigente.

Entre as inúmeras homenagens que recebeu, destacamse, em 1960, a Medalha Comemorativa do Centenário da Escola do Hospital São Tomas, criada pela ABEn, com a efígie de Florence Nightingale; em 1963, a comemoração realizada na EEAN pelos 25 anos de sua formatura, ocasião em que a EECC sefez representar; em 1968, o prêmio Enfermeira do Ano, oferecido pela $A B E n^{15}$; em 1983, o título de "Professor Honoris Causa" outorgado pela Universidade Federal do Rio de Janeiro. ${ }^{4}$

Waleska Paixão aposentou-se em 1970 e nos vinte anos seguintes, dedicou-se a trabalho pastoral na Arquidiocese do Estado de Sergipe. Devido a problemas de saúde, retornou a Petrópolis, onde faleceu em 25 de novembro de 1993. Determinação e persistência são características dessa personagem.

\section{CONSIDERAÇÕES FINAIS}

Esta pesquisa sócio-histórica teve como protagonista uma personagem que viveu toda a sua vida imbuída do espírto de serviço em prol da enfermagem. Neste estudo foi possível trazer à tona fragmentos da trajetória pessoal e profissional de Waleska Paixão, mostrando o seu envolvimento com o campo da educação e da saúde e algumas de suas contribuições para o desenvolvimento da enfermagem brasileira.

Waleska Paixão demonstrou ser uma intelectual comprometida com a sociedade em que se insere. Sua condição de aluna, professora e diretora da EECC e, posteriormente, de professora e diretora da Escola de Enfermagem Anna Nery, perfazendo um período de vinte e cinco anos na gestão das primeiras escolas de enfermagem brasileiras e de membro atuante naABEn, faz dela uma figura de destaque no campo do ensino e da enfermagem do País.

\section{REFERÊNCIAS}

1. Paixão W. Páginas de história da enfermagem. Rio de Janeiro(RJ): Universidade do Brasil; 1951.

2. Alves APC, Silva Júnior OC. Páginas de história da enfermagem: 0 jubileu de ouro de uma obra (1951-2001). Esc Anna Nery Rev Enferm 2006 ago; 10(2):181-86.
3. Coelho CP. Escola de Enfermagem Anna Nery: sua história, nossas memórias. Rio de Janeiro(RJ): Cultura Médica; 1997.

4. Nascimento ES, Santos GF, Caldeira VP. Criação, quotidiano e trajetória da Escola de Enfermagem da UFMG: um mergulho no passado. Belo Horizonte(MG): EECC/UFMG; 1999.

5. Azevedo JM, Carvalho V, Gomes MLB. Waleska Paixão: uma biografia a serviço da enfermagem brasileira. Esc Anna Nery Rev Enferm 2009 jan-mar; 13(1): 31-5.

6. Bourdieu P. A ilusão biográfica. In: Amado J, Ferreira M, organizadores. Usos e abusos da história oral. Rio de Janeiro(RJ): Fundação Getúlio Vargas; 1996. p.183-191.

7. Paixão W. Entrevista concedida às professoras leda de Alencar Castro Barreira e Raimunda da Silva Becker. Rio de Janeiro(RJ): ABEn/EEAN; 1998. 3 fitas.

8. Paixão W. História da enfermagem. $5^{\mathrm{a}}$ ed. Rio de Janeiro(RJ): Júlio C. Reis; 1979.

9. Bourdieu P. 0 poder simbólico. Rio de Janeiro(RJ): Bertrand Brasil; 1989.

10. Santos GF. Escola de Enfermagem Carlos Chagas: à Deus, pela humanidade, para o Brasil. [tese de doutorado]. Belo Horizonte (MG): Faculdade de Educação/UFMG; 2006.

11. WP. Ficha de inscrição. Belo Horizonte (MG): Centro de Memória Escola de Enfermagem/UFMG; 1939.

12. Cardoso A. Internato Carlos Chagas: seu histórico. A Enfermagem em Minas 1936 set;1(1): 52-65.

13. Paixão W. Nova etapa. Cinco p'ras Dez, Belo Horizonte, 1936 jul ; 2 (12) .

14. Araújo MA de. História da Escola de Enfermagem Hermantina Beraldo: gestão Celina Viegas [dissertação de mestrado]. Belo Horizonte (MG): Escola de Enfermagem/UFMG; 2002.

15. Carvalho AC. Associação Brasileira de Enfermagem-1926 1976: documentário. Brasília(DF): ABEn; 1976. 